\title{
THE FORMANT CONSTRUCTION OF JAPANESE VOWELS
}

\author{
TOSHIHIKO TOKIZANE ${ }^{1}$ \\ Department of Physiology, Medical Faculty, Tokyo University, Tokyo
}

DEFINITION OF FORMANT

The timbre of sound, whether musical or noisy, periodic or nonperiodic, is generally taken as due to the structural pattern of partial vibrations, of which the sound is composed. In the case of a musical sound, it is, according to Ohm's law, the structural pattern of partial vibrations of definite frequencies and amplitudes, that is the acoustic spectrum, that determines the timbre, and, accordingly, we can represent the timbre of a musical sound simply by its acoustic spectrum, which is by no means difficult to obtain. In the case of noise, however, there is besides the structural pattern of spectrum, another important factor, that is, the mode of its characteristic temporal variation. Many works hitherto performed in this field suggest, however, that the former would play a more important part in characterizing the timbre of noise than the latter, and so it will perhaps be proper to put the temporal variation aside for the moment, and to assume that the timbre of noise is characterized, mostly at least, by the structural pattern of the spectrum. It is, however, almost impossible in most cases to determine the precise structural pattern of spectrum of noise, and even if possible, it needs a very troublesome procedure for doing so. We have, therefore, to be satisfied with the mean structural pattern obtainable from a wave in a given interval of time.

Be the wave periodic or nonperiodic, the structural pattern of its spectrum is called the Formant construction of sound, of which the main groups of partial vibrations (in the case of musical sound) or the main partial vibrations themselves (in the case of noise or vowels, voiced and whispered) are called the Formants, signifying the characteristic frequency regions. We can thus generally express the timbre of sound in terms of Formant construction. But when doing so, we should bear in mind that the mode of the temporal variation is being disregarded as to noise and whispered vowel.

In the case of violin, for example, one violin is different from another in timbre as well as in Formant construction. Despite this, we can designate their timbres as that of "violin in general," differentiating it from the timbres of other kinds of musical instruments. This fact shows that the timbre of "violin in general" is characterized by a Formant construction of broader frequency regions, which at least includes all Fomants of "individual violins." Such a generalized or abstract Formant construction of any kind of musical instrument

1 時実利彥

Received for publication December 8, 1950. 
is called the Formant construction of that instrument. In one kind of musical instrument, the Formant of each individual instrument is, as the acoustics show, a group of partial vibrations, and, therefore, the generalized Formant of that instrument has certain definite frequency regions of some degree.

The same argument can be made for the timbre of a vowel. Japanese vowels are classified into five, i.e., ア(a), イ(i), ウ(u), エ(e) and オ(o). The timbre of $\gamma(\mathrm{a})$ and its Formant construction when articulated by one person are different from those articulated by another, and yet we can recognize, as a whole, the timbre of " $>(a)$ in general." This Formant construction of " $\gamma(a)$ in general," in which all Formants of every "individual $>(a)$ " are included, is called the Formant construction of vowel $>(a)$. The Formant construction of $>(a)$ of one person is, as we shall see below, essentially different from those of musical instruments, and shows itself almost as a partial vibration with a certain definite frequency, while the Formant of " $>$ (a) in general" has a difinite frequency region as the Formants of musical instruments do, because it embodies all Formants of every "individual $>(a)$ " in it.

\section{METHOD OF FORMANT DETERMINATION (ANALYSIS OF SOUND WAVE OF VOWEL)}

The researches on determination of the Formant construction of vowel will be most reasonable when performed in direct connection with the phonatory mechanism. The analysis of sound wave has mostly been made by means of Fourier's harmonic analysis. This method, being originally one of mathematical approximation applied to a part of a curve arbitrarily chosen, does not give any information of the physical structural feature of the sound wave. It is available when the sound wave in question is strictly periodic and previously known to be constructed with harmonic partial vibrations, but it is not useful at all for the analysis of nonperiodic sound waves constructed with nonharmonic partial vibrations or of sound waves whose physical structures are unknown.

The reason why the method of harmonic analysis has been used for the analysis of the sound wave of vowel is that the wave is apparently a periodic one like those of musical instruments. But, as seen in fig. 1 , the wave is not strictly periodic, and indeed there is no physical basis to regard that the sound of vowel is constructed with harmonic partial vibrations (1). Further, we recognize that the wave of a certain vowel, when articulated by one person in various pitches, with no change in the form of the mouth and other accessary cavities, appears to be built up of a particular fundamental wave, i.e., with a wave proper to that vowel, which is periodically repeated with a definite interval corresponding to the pitch of articulation (fig. 2). These facts suggest strongly that the phonatory mechanism of vowel is quite different from that of a musical sound. Indeed, the wave of a musical sound is composed of harmonic or nonharmonic partial vibrations added algebraically, and if it is periodic, the wave form of one period is necessarily identical with that of the following period, being mutually dependent on each other. The sound wave of a vowel is also periodic, but, in contrast to a musical sound, it is built up of a "proper wave" serially connected with definite intervals corresponding to the pitch of articulation, 
(1)

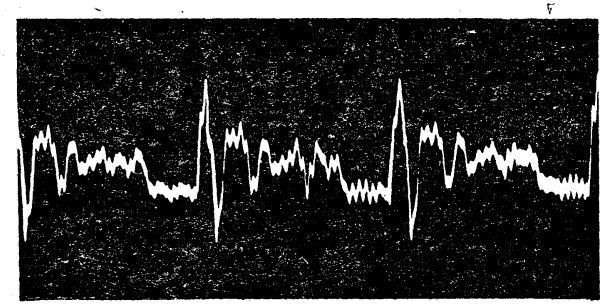

$101 \propto$

$98 \infty$

$96 \nsim$

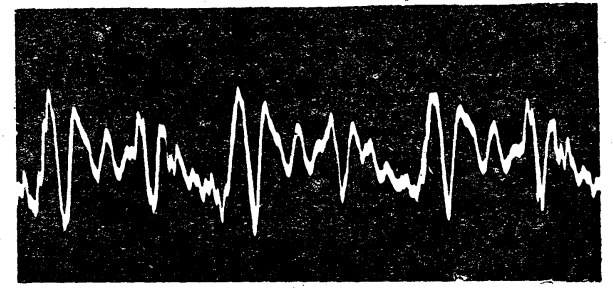

$102 \nsim$

$98 \infty$

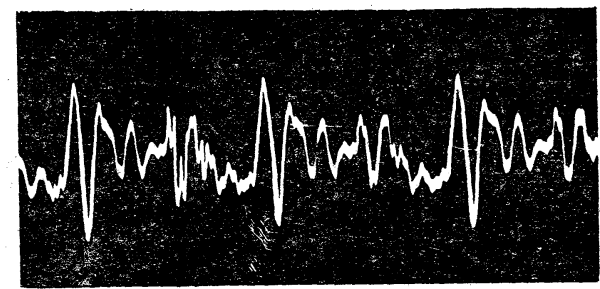

101 s

$97 \infty$

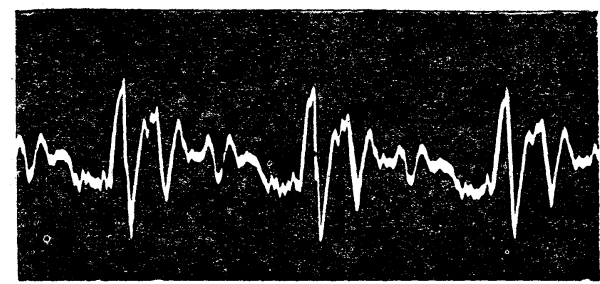

$101 \infty$

$102 \nsim$

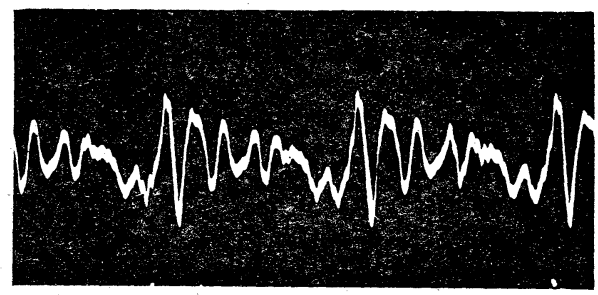

98

$97 \infty$

munumunuturuts $\leftarrow$ Fig. 1. Temporal variations of periods and wave forms of Japanese vowel $>(a)$, voiced. Records taken in succession (1) $\rightarrow(2) \rightarrow(3) \rightarrow(4) \rightarrow(5)$ in 2 seconds interval. Articulated in pich A. Subj.: Y. K., male adult. Time: $1,000 \mathrm{cps}$.

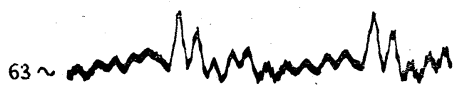

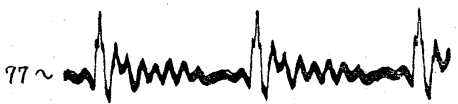

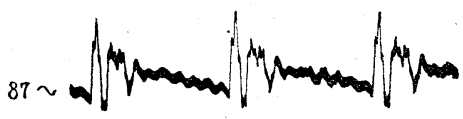

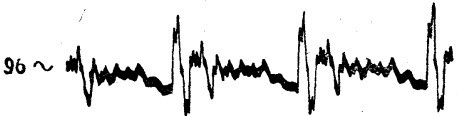

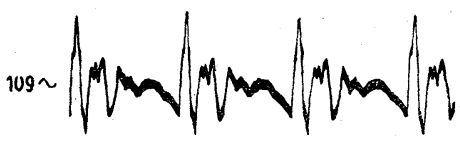

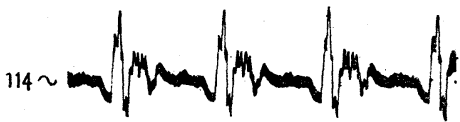

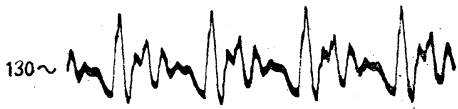
$142 \sim \ln \mid \ln \| \operatorname{man} \int \operatorname{man}$ ${ }^{150} M_{W} M_{W} W_{W} W_{W} W_{W}$

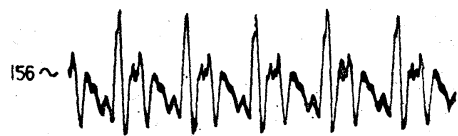

$\uparrow$ Fig. 2. Wave forms of the Japanese vowel $\zeta(a)$ articulated by a person in various pitchs. Subj.: I. K., male adult. 
the wave form of each period being mutually independent of one another (2). This view finds support in the observations of vocal cords' movements during articulation of vowel (3), as well as in those on a larynx-model which was constructed from frog's thigh muscles (4).

As shown in fig. $3(a)$, the "proper wave" of each vowel can be regarded

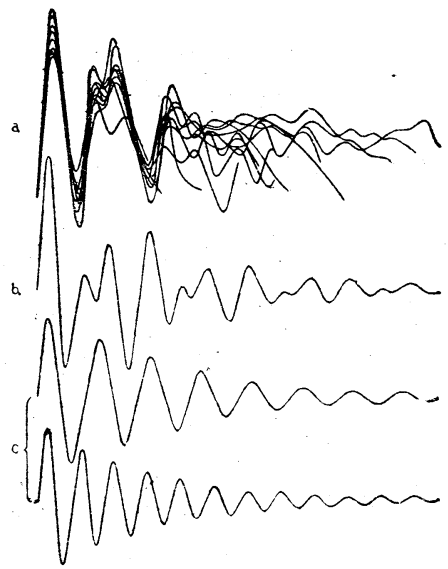

Fig. 3.

(a): Ten waves of vowel $\Gamma(\mathrm{a})$ in one period (fig. 2) superposed.

(b): The wave composed of two partial damped vibrations in $(c)$, of which one is of a frequency 650 cps., of a logarithmic damping constant 0.39 , and of an amplitude 1.0 and the other of a frequency $940 \mathrm{cps}$., of a logarithmic damping constant 0.26 , and of an amplitude 0.8 . The similarity of $(a)$ with $(b)$ indicates that the wave $(b)$ can ke regarded as the "proper wave" of vowel $\boldsymbol{\gamma}(\mathrm{a})$.

as a compound damped vibration composed of partial damped vibrations with definite amplitudes, frequencies and damping constants. These partial damped vibrations are nothing but Formants of each vowel.

Now for determining the Formant construction of a vowel, the problem arises as to how to analyse its "proper wave," a compound damped vibration. Generally, this type of analysis is not so easy as an harmonic analysis and no attempts have yet been made. Fortunately, the present author did succeed relatively easily to analyse the vowel waves by means of parallel employment of several methods, namely, the method of inspection, the method of harmonic analysis, the electrical and mathematical methods of inverse synthesis, etc (5). Fig. 3 is an example illustrating this procedure.

The analysis of a whispered vowel will be found below in chapter 'results 2).'

\section{RESULTS}

\section{1) Determination of Formant construction of Japanese voiced vowel}

The Formant construction of Japanese voiced vowels has been discussed by many authors but with no clear explanation. The present author and Y. Katsuki once reported some results obtained by the procedure mentioned above (6), but as there were some small imperfections, the problem was attacked anew by the present author.

Subjects examined were 15 adult men, 10 adult women and 4 children. For recording the sound wave of vowel, microphones of the moving coil type and rochelle salt type, an ordinary resistance-capacity coupled amplifier and an electromagnetic oscillograph (Yokogawa Co.; A- and C-type vibrators) were used. 

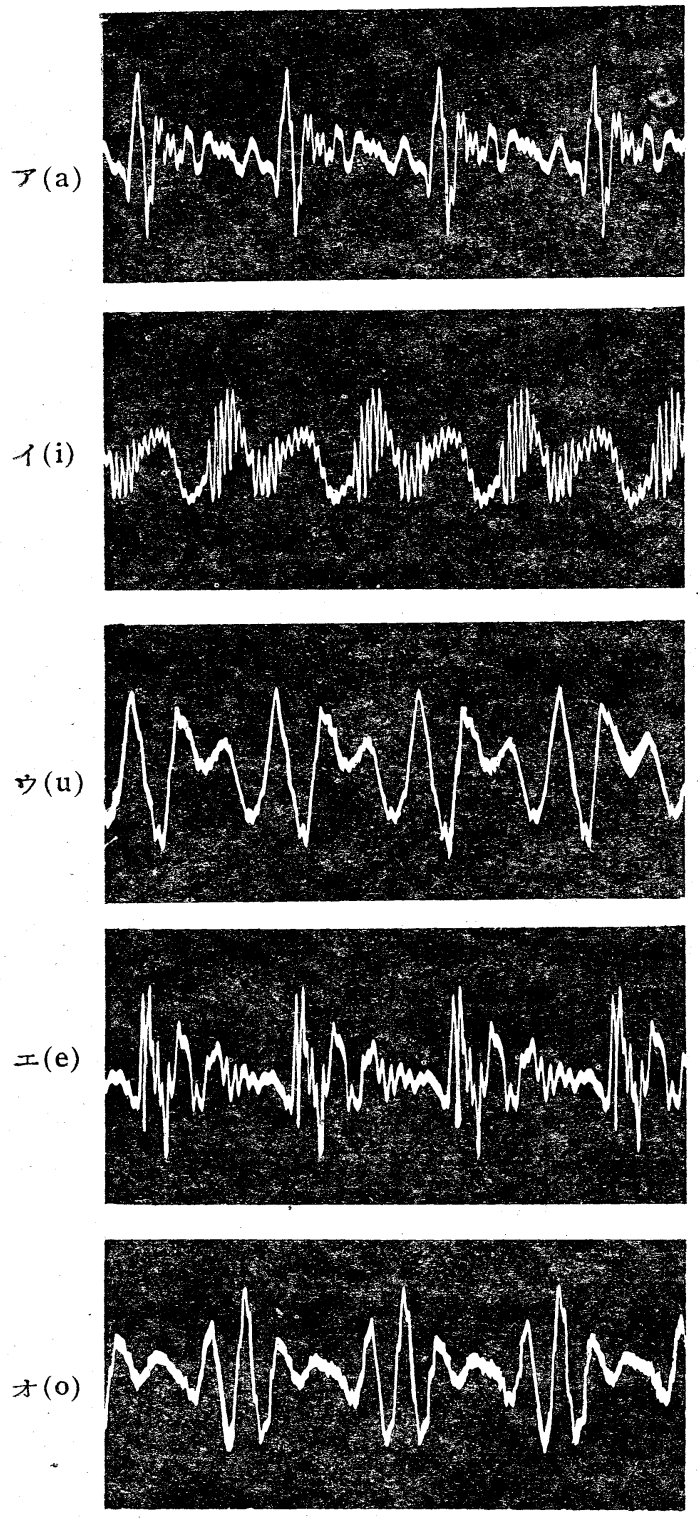

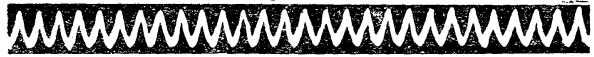

Fig. 4. Wave forms of Japanese voiced vowels articulated by an adult man in pitch, c. Subj.: H. M., Time: $1,000 \mathrm{cps}$.
Distortions due to the transformation-amplification-recording system were avoided as much as possible. For certain unavoidable distortions which did mingle, corrections were made later in the course of analysis, taking the frequency-characteristic curve of the whole system into account.

Fig. 4 shows one of the recorded waves. On such a wave, analysis was made in two ways. One was one of the various methods described above, and the other the method of electrical frequency analyser (Yokogawa Co.). Fig. 3 and 5 are examples of these two methods respectively.

In fig. 6 and table 1 are summarized the results of analysis, where we see that all five Japanese voiced vowels have six Formants respectively. Of these Formants, $F_{1}$ and $F_{2}$ of large amplitudes, which characterize each vowel, may be called the main Formants. They originate most probably from the natural vibrations of the mouth and other accessary cavities, because, on the one hand, the frequencies of these Formants approximately coincide with the theoretically computated natural frequencies of these cavities taken as a compound sound cavity as a whole (7), and, on the other hand, they precisely agree with the directly measured natural frequencies of these cavities (8). $f_{1}$ and $f_{2}$ are overtones of $F_{1}$ and $F_{2}$ respectively. As seen in table 1 , Ratio $f_{1}: F_{1}$ and $f_{2}: F_{2}$ are not representable with integer numbers, which is resonable if viewed from the theory of acoustics (9). $F_{l}$ 


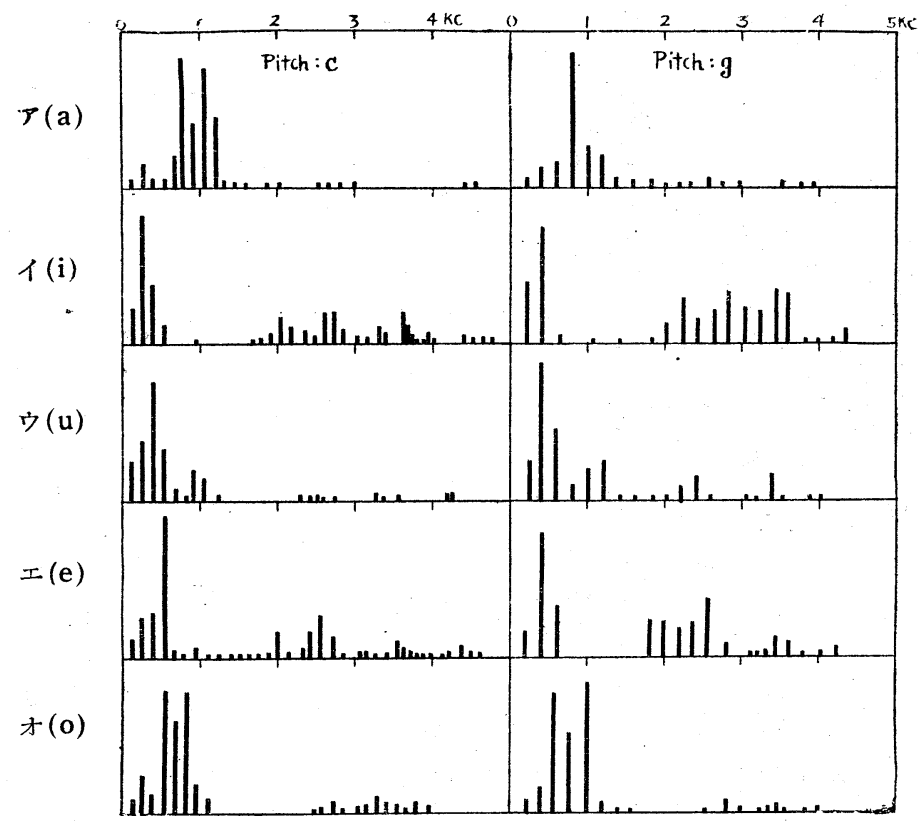

Fig. 5. Structural patterns of spectrum of Japanese voiced vowels obtained by means of an electrical frequency analyser. Subj.: Y. K., male adult.
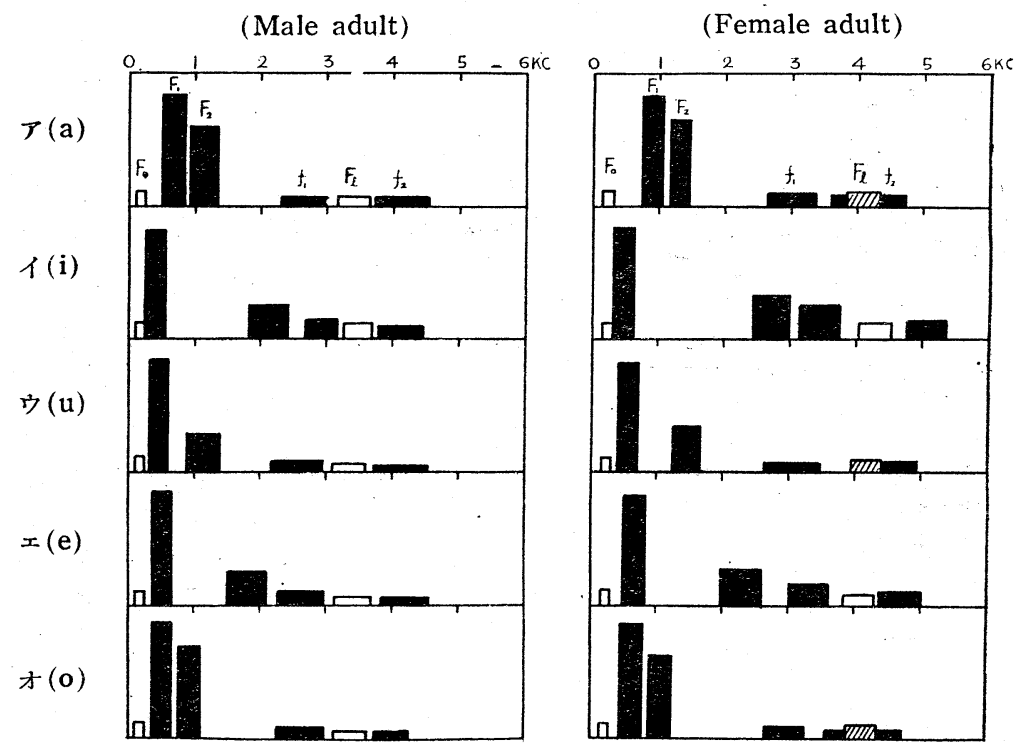

Fig. 6. The Formant constructions of the Japanese voiced vowels. 
Table 1. The frequency regions of Formants of the Japanese vioced vowels

\begin{tabular}{|c|c|c|c|c|c|c|c|c|c|}
\hline & & $F_{0}$ & $F_{1}$ & $F_{2}$ & $f_{1}$ & $F_{l}$ & $f_{2}$ & $f_{1}: F_{1}$ & $f_{2}: F_{2}$ \\
\hline $\begin{array}{l}\text { Male } \\
\text { adult }\end{array}$ & 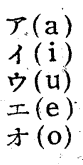 & $\begin{array}{l}100-250 \\
100-250 \\
100-250 \\
100-250 \\
100-250\end{array}$ & $\left|\begin{array}{ll}500- & 870 \\
250- & 560 \\
300- & 620 \\
350- & 670 \\
340- & 670\end{array}\right|$ & $\begin{array}{r}920-1,360 \\
1,800-2,420 \\
900-1,400 \\
1,500-2,050 \\
750-1,100\end{array}$ & $\begin{array}{l}2,300-3,020 \\
2,650-3,180 \\
2,150-2,980 \\
2,250-3,000 \\
2,220-2,970\end{array}$ & $\mid \begin{array}{l}3,150-3,650 \\
3,250-3,700 \\
3,050-3,600 \\
3,100-3,700 \\
3,100-3,560\end{array}$ & $\mid \begin{array}{l}3,700-4,550 \\
3,750-4,460 \\
3,700-4,550 \\
3,800-4,550 \\
3,720-4,250\end{array}$ & $\begin{array}{l}3.8 \\
7.2 \\
5.6 \\
5.1 \\
5.1\end{array}$ & $\begin{array}{l}3.6 \\
1.9 \\
3.6 \\
2.4 \\
4.3\end{array}$ \\
\hline $\begin{array}{c}\text { Female } \\
\text { adult }\end{array}$ & $\begin{array}{l}P(\mathrm{a}) \\
イ(\mathrm{i}) \\
\eta(\mathrm{u}) \\
x(\mathrm{e}) \\
才(\mathrm{o})\end{array}$ & $\begin{array}{l}150-300 \\
150-300 \\
150-300 \\
150-300 \\
150-300\end{array}$ & $\mid \begin{array}{l}700-1,070 \\
300-630 \\
400-730 \\
500-840 \\
430-820\end{array}$ & $\begin{array}{r}1,180-1,500 \\
2,400-2,950 \\
1,220-1,650 \\
1,950-2,600 \\
900-1,280\end{array}$ & $\mid \begin{array}{l}2,600-3,320 \\
3,100-3,750 \\
2,600-3,470 \\
3,000-3,640 \\
2,650-3,300\end{array}$ & $\begin{array}{l}3,850-4,300 \\
4,000-4,450 \\
3,920-4,400 \\
3,860-4,270 \\
3,900-4,400\end{array}$ & $\begin{array}{l}3,540-4,750 \\
4,750-5,360 \\
3,920-4,950 \\
4,400-5,050 \\
3,560-4,750\end{array}$ & $\begin{array}{l}3.3 \\
7.4 \\
4.5 \\
4.9 \\
4.8\end{array}$ & $\begin{array}{l}3.1 \\
1.9 \\
3.1 \\
2.1 \\
3.8\end{array}$ \\
\hline
\end{tabular}

is the Formant common to all the vowels and may be regarded as due to the natural vibration of the laryngeal cavity. $F_{0}$, having the frequency region common to all the vowels, is the Formant corresponding to the slow undulation which appears particularly clearly in the case of low pitch articulation (fig. 7), and we are perhaps right in regarding it as due to the opening and closing movements of the vocal cords during articulation (10). Further, it was assured experimentally that $F_{1}$ and $F_{2}$ (the main Formants) play the major role and the others (the sub-Formants) the minor but finer role in characterizing the timbre of vowel (11). The main Formants are indispensable for the characterization of vocality and are present in all cases, while the sub-Formants, which perhaps play just an ornamental role, do not always exist, or appear differently according to different individuals or to different manners of articulation.

The Formant constructions of women's vowels show similar features as men's (fig. 6 and table 1), and there is no essential difference between them except that the frequency regions of women's Formants as a whole, slightly shift to those of higher pitches in comparison with men's. The Formant constructions of children show the same features as women's. Such a shift of frequency region as found in the Formant constructions of women and children can readily be explained by the smaller sizes of their mouths and other accessary cavities in comparison to men's (9).

\section{2) Determination of Formant construction of Japanese whispered vowel}

The whispered (unvoiced) vowel is called by this name when the vowel is articulated without movements of the vocal cords. It seems, as seen in fig. 8, a nonperiodic and irregular wave like that of noise. Accordingly the timbre of whispered vowel is, as discussed in chapter 'definition of Formant,' expected to be characterized by the structural pattern of spectrum and by the mode of its temporal variation as well. In reality, the randomness of the temporal variation of partial vibrations characterizes the "whisper" itself, while the structural pattern of spectrum the vocality (12).

It is so troublesome to determine the precise structural pattern of spectrum of whispered vowel that no-body has ever attempted to do it. The present author is perhaps the first who succeeded in determining it. He determined, at first, the mean structural pattern of whispered vowel by means of an electrical frequency analyser and a band-pass filter. Next, the determination of the precise 

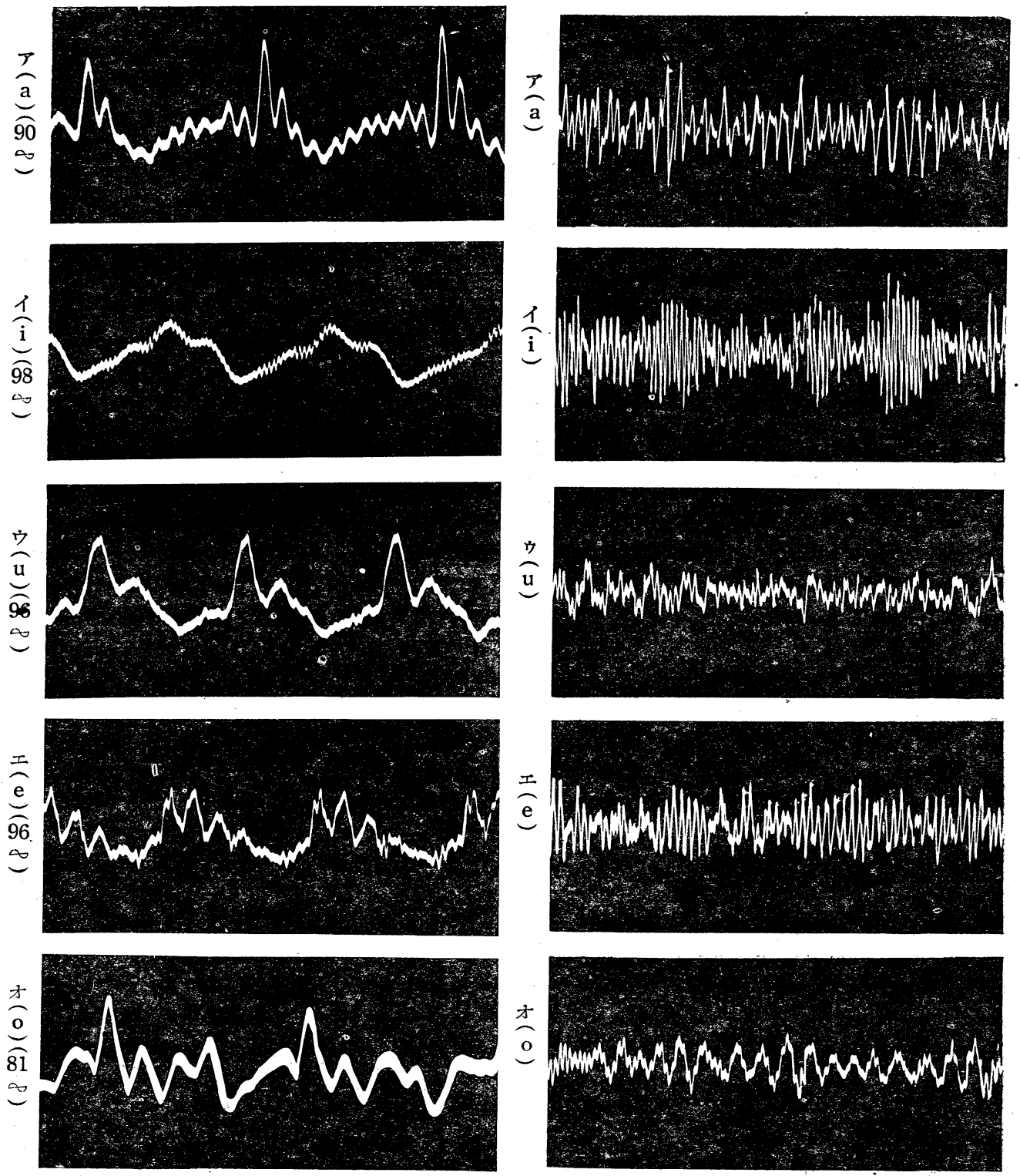

\section{munumunumunut}

Fig. 7. wave forms of Japanese voiced vowels in low pitch articulations.

Subj. : Y. K., male adult.

Time: $1,000 \mathrm{cps}$.

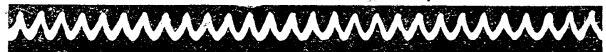

Fig. 8. Wave forms of Japanese vowels whispered.

Subj.: I. K., male adult.

Time: $1,000 \mathrm{cps}$. 
structural pattern of spectrum was made with the following considerations. Taking the phonatory mechanism of a whispered vowel, as will be described below, in account, we assume that the wave is built up of partial damped vibrations of definite frequencies appearing in a random manner. If, accordingly, the serial correlation coefficient, that is, the correlogram, is calculated from the wave in a given interval of time, we can obtain a curve which is composed of partial damped vibrations of definite frequencies and amplitudes and of the same initial phase. Applying, then, to this curve the method of analysis of the compound damped vibration, we can obtain the frequency, amplitude and damping constant of each partial damped vibration, that is, the Formant of whispered vowel. Fig. 9 illustrates the procedure for this type of analysis.

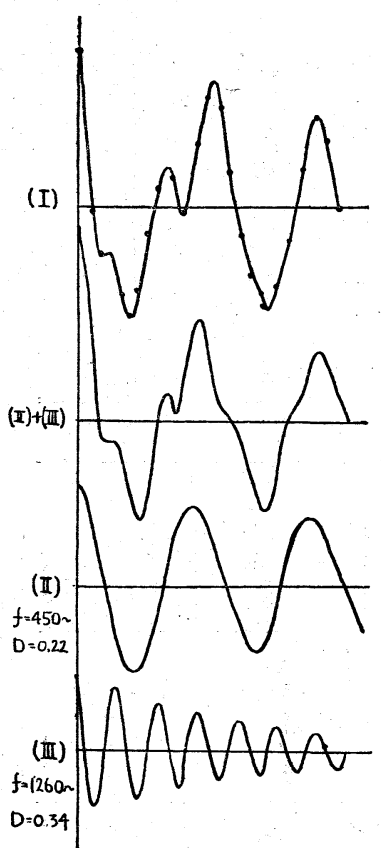

Fig. 9. Analysis of the Japanese whispered vowel $ウ(u)$ (fig. 8) by the method of correlogram.

(I): The curve obtained from the original wave; (II), (III) : partial damped vibrations obtained from the curve (I) by the method of analysis of the compound damped vibration; (II) + (III) : the curve constructed with curves (II) and (III), showing a similar appearance to the curve (I). $f$ : frequency; $D:$ logarithmic damping constant.

In fig. 10 and table 2 are shown the mean structural patterns, that is, the Formant constructions of whispered vowel, thus obtained. As seen in fig. 10 and in fig. 6 , the Formant constructions of whispered vowels are generally much alike those of voiced vowels. Small differences exist in 1) that the frequency regions of Formants of whispered vowels are, as a whole, shifted a little towards the higher pitch, and 2) that the relative amplitudes of each Formant differ not a little from those of voiced vowels. These differences may be attributed to the shapes of the mouth and other accessary cavities which will be more or less different in articulations of voiced and whispered vowels, and also to the different features of the phonatory mechanism itself. The Formant corresponding to $F_{0}$ which appears in voiced vowel is absent in whispered vowel, which is only natural because the movements of the vocal cords, necessary for producing $F_{0}$, do not take place in the articulation of whispered vowel. 

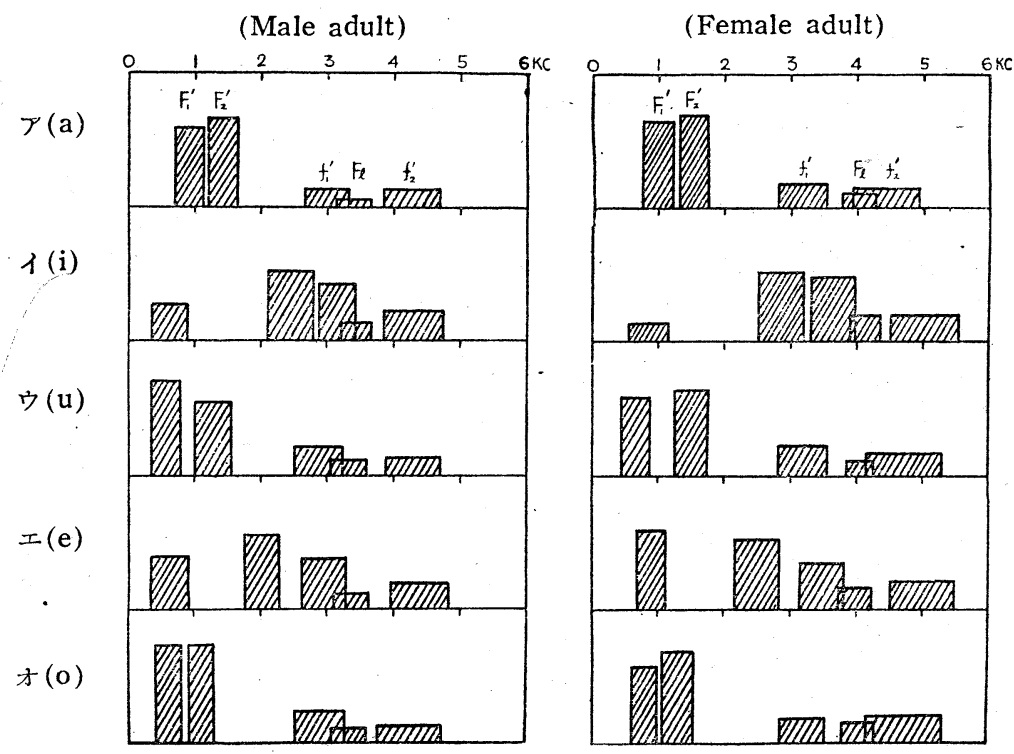

Fig. 10. The Formant constructions of the Japanese whispered vowels.

Table. 2. The frequency regions of Formants of the Japanese whispered vowels

\begin{tabular}{|c|c|c|c|c|c|c|}
\hline & & $F_{1^{\prime}}$ & $F_{2^{\prime}}$ & $f_{1}^{\prime}$ & $F_{l}^{\prime}$ & $f_{2}^{\prime}$ \\
\hline Male adult & $\begin{array}{l}ア(\mathrm{a}) \\
イ(\mathrm{i}) \\
ウ(\mathrm{u}) \\
エ(\mathrm{e}) \\
\text { オ }(\mathrm{o})\end{array}$ & $\begin{array}{l}700-1,150 \nsim \\
350-900 \\
350-700 \\
350-950 \\
400-850\end{array}$ & $\begin{array}{r}1,200-1,620 \\
2,100-2,800 \\
1,000-1,550 \\
1,750-2,300 \\
900-1,300\end{array}$ & $\begin{array}{l}2,650-3,320 \\
2,850-3,450 \\
2,500-3,250 \\
2,600-3,300 \\
2,500-3,250\end{array}$ & $\begin{array}{l}3,120-3,650 \\
3,220-3,700 \\
3,050-3,600 \\
3,100-3,650 \\
3,050-3,600\end{array}$ & $\begin{array}{l}3,850-4,670 \\
3,850-4,750 \\
3,900-4,700 \\
3,950-4,850 \\
3,750-4,750\end{array}$ \\
\hline Female adult & $\begin{array}{l}P(\mathrm{a}) \\
イ(\mathrm{i}) \\
ウ(\mathrm{u}) \\
x(\mathrm{e}) \\
\text { オ(o) }\end{array}$ & $\begin{array}{l}750-1,250 \\
550-1,150 \\
450-850 \\
630-1,100 \\
550-950\end{array}$ & $\begin{array}{l}1,300-1,750 \\
2,500-3,200 \\
1,200-1,750 \\
2,120-2,800 \\
1,000-1,500\end{array}$ & $\begin{array}{l}2,800-3,550 \\
3,300-3,950 \\
2,800-3,550 \\
3,100-3,800 \\
2,800-3,500\end{array}$ & $\begin{array}{l}3,750-4,300 \\
3,900-4,350 \\
3,850-4,250 \\
3,700-4,200 \\
3,750-4,250\end{array}$ & $\begin{array}{l}3,920-4,920 \\
4,500-5,550 \\
4,150-5,300 \\
4,450-5,400 \\
4,100-5,250\end{array}$ \\
\hline
\end{tabular}

The observations described above lead us to the conclusion that the whispered vowel is articulated by the natural vibrations of the mouth and other accessary cavities, being evoked in a random manner by the flow of expiratory air through the narrow gap between the vocal cords. The experiment on the larynx-model supports this view, too (4).

\section{CONCLUSION}

The results obtained in the above experiments have led us to the following conclusions. Each vowel, voiced and unvoiced, is constructed by two main Formants and several sub-Formants, four for voiced vowel and three for whispered vowel, of which the former characterize the vocality as a whole, and the latter the individual finer characters of the vocality respectively. The main Formants are ascribed to the natural vibrations of the mouth and other accessary cavities 
particularly shaped for each vowel respectively, and the sub-Formants $f_{1}, f_{2}$; $F_{l} ; F_{0}$, to the overtones of those main Formants, the natural vibration of the laryngeal cavity and to the movements of the vocal cords respectively. The nature of "whisper" lies in the temporal variation of each partial vibration of which the whispered vowel is built.

As to the phonatory mechanisms of voiced and whispered vowels, we would say that they both are the natural vibrations of the mouth and other accessary cavities, and that the vibration is evoked periodically by the opening and closing movements of the vocal cords in the former case, and in a random manner by the flow of expiratory air through the narrow gap of the vocal cords in the latter case.

A natural question arises here, namely, why the main Formants do bestow the timbres of $>(\mathrm{a}), イ(\mathrm{i}), \boldsymbol{\eta}(\mathrm{u}), x(\mathrm{e})$ and $才(0)$, i.e., the vocality, and the temporal variation of partial vibrations the nature of whisper. According to the recent advances in physiology of audition, the sound wave, of whatever feature or whatever constructional mechanism it may be, is analysed at the basilar membrane of the cochlea to be transformed to such a special pattern of excitation there, as is presumed by the Helmholtz's resonance theory. And this excitatory pattern at the basilar membrane evokes a similar topological pattern of excitation in the auditory area of the cortex after the principle of point-to-point correspondence between the basilar membrane and the auditory area (13). After all, any given sound wave is believed to evoke a corresponding specific pattern of excitation in the auditory area. This is all the knowledge which we possess at present. To the question, why, then, a given pattern of excitation in the auditory area evokes the sensation of a definite timbre of sound, for example, the timbre of violin, the vocality or the nature of whisper, we have not yet any satisfactory scientific answer except such psychological expressions as, for example, "mental activity" acquired by learning and memory, etc. The question, together with other similar ones, is left for future study.

I wish to express my appreciation of the guidance kindly given me by late Prof. K. Hashida and Prof. S. Sakamoto, of the advice given by Prof. K. Satta, and of the helps by Prof. Y. Katsuki and Prof. I. Kirikae.

\section{REFERENCES}

1. YoshikAWA, K. On the temporal variation of the sound waves of vowels. Kagaku (Science) $17: 26,1947$.

2. Tokizane, T. The analysis of the vowel curve. Shindo (Vibration) 1: 118, 1947

3. SATTA, K. The mechanism of phonation and the regulation of articulation. J. Oto. Soc. Jap. $45: 1590,1937$.

KIRIKAE, I. The motion of the vocal cords and the time-relation of the glottis opening during phonation. J. Oto. Soc. Jap. 49: 236, 1943.

4. KIRIKAE, I., T. TOKIZANE AND Y. KATSUKI. The model experiment of the larynx used frog's tigh muscles. Kagaku (Science) 18: 281, 1948; 19:237, 1949.

5. TOKIZANE, T. The method of analysis of compound damped vibrations. unpublished.

6. KATSUKI, Y. AND T. TOKIZANE. The voice. Shizen (Nature) 12: 16, 1947. 
7. Chiba, T. AND M. KaJiYama The vowel. $67,1941$.

8. KATSUKI, Y. The Formant construction of the Japanese voiced vowels and the natural frequency of the mouth and other accessary cavities. Shindo (Vibration) 1: 10, 1947.

9. KATSUKI, Y. AND T. TOKIZANE. The natural frequency of the compound resonator. J. Acous. Soc. Jap. 4 : No. 6, 35, 1943.

The natural frequency of the single resonator. J. Acous. Soc. Jap. 4 : No. 12, 9, 1943.

The conductivity of the resonator. J. Acous. Soc. Jap. 5 : No. 4, 1, 1944.

10. ToKizane, T. On the slow undulation of the vowel curves. The 59th meeting of the physiological society of Tokyo. 1949.

11. TOKIZANE, T. The electrical synthesis of the vowels. unpublished.

12. TOKIZANE, T. AND Y. KATSUKI. The phonatory mechanism and the hearing of whispered vowels. unpublished.

13. WOOLSEY, C. N. AND E. M. WALZL. Topical projection of nerve fibers from regions of the cochlea to the cerebral cortex of the cat. Johns Hopk. Hops Bull. 71: 315, 1942.

ADES, H. W. AND R. E. FELDER. The acoustic projection system: A comparative study. J. Neurophysiol. 8 : 463, 1945.

TUNTURI, A. R. Audio frequency locarization in the acoustic cortex of the dog. Amer. J. Physiol. 141 : 397, 1944. 